\title{
Emotional labour and the pursuit of the personal brand: Public relations practitioners' use of social media
}

\author{
Liz Bridgen, Department of Film, Media and Journalism, De Montfort \\ University, Leicester, UK LE1 4BH
}

\section{Email: ebridgen@dmu.ac.uk}

Biography: Liz Bridgen is Senior Lecturer, Public Relations at De Montfort University, Leicester. She is Programme Leader for the University's MA in Public Relations

\begin{abstract}
The potential of social media to alter models and modes of public relations practice has attracted the attention of both academics and organisations. However, public relations-related research effort has focussed on organisational issues, applications of technology and the impact of social media on public relations theory and practice. Consequently, little attention has been given to the impact of work-related use of social media on practitioners' lives.
\end{abstract}

Practitioners have historically been encouraged to use their feelings and emotions when liaising with journalists and clients. While Yeomans (2007:218) describes this as "learning to please," the character of new media work as expressed by Gill (2002) and Kennedy (2009) means that employees may also derive pleasure from the online conversations and connections carried out on behalf of their employers and will use these connections to further their own career. However, this use of the self to build an online personal brand and form meaningful and mutually beneficial workrelated relationships with individuals online (which will include bloggers and opinion formers as well as journalists and clients) means that the practitioner's emotions become part of the employer's product and subsequently responsible for some aspects of organisational success. 
Drawing on interviews with public relations practitioners, this article looks at one particular aspect of the public relations role - the involvement in online conversations via social media - and considers how far this relationship, where a practitioner is acting simultaneously as a professional worker and a private individual, can be analysed in terms of 'emotional labour' (Hochschild, 1983). This article explores whether the pleasure that public relations practitioners derive from online work, the freedom it gives them to work remotely, and the licence it gives them to build their own personal brand and work in areas that interest them personally also serves to hide exploitation, legitamise long working hours and reaffirm existing gender roles within the profession. Conversely, the article also explores whether the use of the personal in online work marks the transition to a more flexible form of employment where a symbiotic relationship between employee and employer exists and where there is no longer a divide between what is classified as work and what is not.

\section{Keywords: Social media; public relations; emotional labour; employment; personal brand}

\section{Introduction}

The communications media used and monitored by public relations practitioners has seen a significant change over the past decade. 'Traditional' media (such as radio, TV, newspapers and magazines) remain common communication tools, but social media are gaining in popularity and have the potential to change the way in which practitioners communicate. What differentiates social media channels (for instance, blogs, microblogging sites such as Twitter, social networking sites, photo and filesharing sites and wikis) from established media types is that they enable the sharing of information on topics relating to an interest or theme among audiences who are niche, global or both and across traditional demarcations. This means that boundaries become blurred and discussions can cross between the professional and the personal with no clear distinction between the two.

The impact of social media on public relations practice has attracted the attention of both academics and organisations due to its potential to open up new opportunities for communication while simultaneously changing the way that organisations 
disseminate and receive information, respond to their stakeholders, and research audience views and motivations. The engagement of individuals and organisations through Internet and social media technologies has resulted in "power in society [...] moving away from its traditional centres in government and business and spreading over a wider social base" (Pieczka, 2006a:282), helping to bring about a shift from a "tell style" (Munter, 2005) of communication to one where the public relations practitioner can monitor or discuss but not dictate or control their organisational message.

Consequently, when disseminating messages to wider audiences, practitioners are now moving towards a situation where they can communicate directly with organisational stakeholders (who may then share, alter, discuss, ignore or exploit their message) via social media channels rather than having their organisational message mediated by journalists or other third parties. The practitioner discourse on the impact of social media technologies on public relations follows a number of strands but in particular addresses how strategies can be adapted to take advantage of technological changes. Richard Edelman, of public relations agency Edelman PR, noted: "We have to be very much part of the conversation by reading key bloggers[...]and to be prepared to contribute to the conversation[...]by having relationships akin to those we have with reporters" (Scoble and Israel, 2006:103). Unpicking his comments, it is clear that the relationship with bloggers (and individuals) online is likely to be even more demanding for public relations practitioners than their relationship with journalists due to the immediacy, volume, and international nature of the online world and the fact that bloggers do not tend to follow journalistic conventions.

Focussing on recent interviews with public relations practitioners, this article looks at one particular aspect of the public relations role; the involvement in conversations via social media by practitioners on behalf of an organisation. It considers how far these conversations and the relationships developed from them, where a practitioner is both acting simultaneously as a professional worker and a private individual, can be analysed in terms of "emotional labour" - where personal attributes are folded into labour relations (Hochschild, 1983). 
The article is organised as follows. Beginning with a short overview of the role of the public relations practitioner and discussion of how they engage with social media in terms of public relations practice, it then explores the notion, and criticisms of, emotional labour, especially in relation to issues of gender within professional and flexible work. After reviewing the literature on emotional labour in public relations practice (Aldoory (2005), Pieczka (2006b) and Yeomans (2007)), it then examines new research into the experiences of public relations practitioners working online.

The study of emotional labour and online public relations practice is of relevance due to the key role that emotion plays in day-to-day public relations activities and thus its connection with both individual and organisational success. As Yeomans (2007:217) observes, "emotion and emotion management skills tacitly accompany the many activities performed by a public relations executive in delivering a personal service to journalists and clients." Similarly, Pieczka (2006b) highlights the importance of "chemistry" in building such relationships and the pivotal role that it plays in the pursuit of success. While these authors were writing about relationships between practitioners and journalists or clients, their comments are equally valid when discussing the work that practitioners are required to carry out online.

\section{The role of the public relations practitioner}

Public relations practitioners work on behalf of an organisation using a "body of practical knowledge[...] pa picture of the world (and a) conceptual frame and working knowledge[...]composed of problems, tools and truths" (Pieczka, 2006a:281). These skills, in the case of public relations agency work, can also be "sold as programmes or campaigns (to) provide a professional solution to a public relations problem" (Pieczka: 2006a:296). They can be emotion or empathy-based, since "friendliness in servicing clients, journalists and management is a requirement of the job" (Yeomans, 2007: 218).

Public relations practitioners are frequently required to monitor and participate in online activity on behalf of the organisations they represent and as such are often comparable with the new media workers discussed by Gill, $(2002,2007)$, Terranova (2000) et al as well as with the customer-facing white collar or service workers researched by Smith Maguire (2008), Brannan, (2005) and Korcynski (2003) et al. 
There are also parallels to be drawn with the discussions regarding TV viewer contributions to online discussion forums (Andrejevic, 2008).

Consequently this article draws on literature which studies white collar and online work as well as public relations practice.

Practitioners stress the need for transparency and authenticity in online conduct which, in this context, encompasses clarity and truthfulness in terms of who the practitioner is representing and the purpose of their online engagement. To rely strictly on corporate language in such conversations - especially when they are dealing with non-corporate users of social media - would be inappropriate.

Consequently, practitioners are required to be highly reflexive and adaptable in their communication and are required to "present (themselves) on different occasions in two or more ways, as bohemian and conventional, as romantic and formal" (Phillips and Young 2009:262). Practitioners also need to understand, and follow, online conventions which may be radically different from used by 'traditional' media (with some social media platforms having their own unwritten codes of conduct and mores) and sometimes without understanding or knowing the identity, motivations or characters of the people with whom they are dealing. Indeed, this research demonstrated that a sophisticated understanding of social media conventions was vital to practitioner success and promotion.

\section{The intersection of corporate life and the 'brand of me'}

Practitioners have historically been encouraged to use their feelings and emotions when liaising with journalists or other individuals. While Yeomans (2007:218) describes this as "learning to please," the character of new media work as expressed by Gill (2002) and Kennedy (2009) means that employees may also derive pleasure from the online conversations and connections carried out on behalf of their employers. However, this use of the personal means that the practitioner's emotions in terms of their personal connections that they make and the personal interests they are willing to discuss online for the benefit of their employer also become part of the employer's product and subsequently may be responsible for some aspects of organisational success. 
Korcynski (2003:57) observes that service workers are likely to have been recruited on the basis of pro-customer attitudes and beliefs and that "recruitment on the basis of pro-customer attitudes can be seen to be tapping into wide social mores of consumption-based identity." Furthermore, Korcynski notes that the interactions which service work provides are not resented but form a "significant and satisfying" aspect of it. This was apparent in this research where the use of the self was seen as essential not just in terms of organisational or personal success but also in providing enjoyment and self-fulfilment at work, "making the personal the precondition of their professional life" (Smith Maguire, 2008:216).

Beck (2000, in Gill:2002:72) argues that in this "brave new world of work," selling "me" in the marketplace becomes important. This is achieved in public relations practice not just by the quality of work but through practitioners building a public profile (a "personal brand") through online work carried out in both personal and professional contexts. Such is the public relations industry's drive for transparency in online communications that a practitioner is likely to be carrying out this work in their own name whilst also being clear about their organisational affiliation in their narrative. Thus, as is common in many new media industries, the line between 'work' and 'non-work' becomes blurred, since the "lifelong task of 'becoming oneself"' (Smith Maguire, 2008:212) is deeply entrenched in contemporary labour relations and one cannot be unpicked from the other. It would not be considered possible or ethical for a practitioner to simply use their organisation's name in their online work; they have to use their own name as well, and be prepared to reveal aspects of their personal life and personality in order to be considered 'authentic.'

The public relations practitioner will use a similar (or identical) 'self' to their 'work self' in personal representations online - for instance when posting personal 'tweets' on Twitter, writing Facebook status updates or commenting on friends' photos and news. Such interactions may take place both inside and outside the workplace, since the flexibility offered by technology (smartphones are ubiquitous among public relations practitioners) blurs the distinction between what is work and what is not. As Leadbeater and Oakley (1999) observe, the commitment to a career and the drive to self-fulfilment through work (and thus the morphing of career and work) can be viewed as a post-Thatcherite phenonema. However, since a generation (at least) 
have worked in this way, the modus operandi is rarely questioned, with Gill (2002:74) arguing that this leaves the worker open to "isolation and insecurity" due to the need (for reasons which will be explained in this article) to continue to work outside office hours since no-one actually monitors they work that takes place outside the office.

While contact with the public is seen by employees as being a "good feature" of white collar work and one which delivers satisfaction (Bradley, 1999:114), this is not necessarily face-to-face or even spoken. Indeed, computer mediated communications have, in many cases, replaced traditional 'over the counter' forms of address, as Poynter (2002:251) observes: "Where previously most public and private service sector relationships rested on 'local' face-to-face encounters[...]communication technologies have been used to facilitate remote forms of interaction with customers that, nevertheless, seek the emulate the feeling relationship of the direct encounter." Some of the language used in social media encounters confirms this, with words such as 'relationships', 'conversations' and 'engagement' used to signify the depth and personal nature of online interactions.

Brannan (2005:432) develops this idea, believing that relationships between individuals and clients do not have to be one-way but can be "reciprocal and involv(ing) the mutual exchange of symbolic gifts and the trading of small favours [...]directly benefit(ting) the team in the pursuit of its performance objectives." However, the development of such relationships does more than simply benefiting the team; seen through the prism of emotional labour, the employee is using their personality, interests and character to benefit a wide range of people, which will include their employers, the client and themselves.

\section{Emotional labour and the public relations practitioner}

While the role of emotion in the workplace has influenced sociology since the early 1980s, the discussion of emotional labour in relation to public relations practitioners has only come to prominence through recent research by writers such as Aldoory (2005), Pieczka (2006b) and Yeomans (2007). As Yeomans (2007:214) observes, a successful practitioner, in order to "instil and maintain confidence in relationships [...] (is) required to develop specific skills in managing emotion," with Pieczka (2006b) noting that the management of client relationships through empathy and negotiation 
skills is seen as one of the essential professional competencies of a practitioner. Such studies have taken the role of emotion and personality within public relations beyond the "knowledge" module (Van Ruler, 2005) where research within public relations focussed on the rational, problem-solving, and task-based approach. The "turn" towards the study of emotion as a key component of public relations practice can be linked to the study of feminisation and gender divides within the profession, and the perceived gendering of public relations competencies.

Hoschchild saw interactions where feelings were transmuted as ultimately exploitative of a worker who was simply "used to make money" (Hoschchild, 1983:55). However, Hochschild's arguments that workers "performed" feelings that they didn't really hold is problematic, especially in the light of more recent research. The overlap between the personal and professional is now so entwined that is difficult to discern what is real and what is a 'false self.' While some practitioners interviewed felt that they 'held back' on expressing certain views, this was not confined simply to work-related social media use but also when online in their own time. Such is the intertwining of home and office life that it is not possible to unpick who the restraint was for.

Drawing from Hughes' (2003) discussions on the roles played by emotions at work, it is clear that lines between personal and business life are not clearly defined by employee or employer. It is useful to bring Bolton and Boyd's (2003:290) critique of Hoschschild's work to the discussion at this point. Bolton and Boyd suggest that "employees may exert an "active and controlling force" in relationships with both management and customers" (2003:290) and if given the freedom to do so, will "give a little extra" (2003:290) due to a sense of duty to colleagues. Within a public relations context, colleagues could also include clients or even the output of the organisation itself - thus, practitioners are using their emotions in a complex way which goes beyond Hoschschild's analysis.

However, while the 'freedom' that many public relations practitioners are given to choose how they structure their day and, often, where they work may lead to a greater sense of freedom (and this research showed that 'keeping on top of' online discussions outside working hours was seen positively as it helped practitioners to 
work effectively the next day) it can also be exploitative since the work is unseen by management.

Authors such as Korczynski (2002: 57) support the view that emotional labour can be "pleasurable" with the pleasure deriving from interactions with customers due to customers being a "key source of meaning." To this end, Korczynski observes that Hochschild's framework fails to acknowledge the pleasure that workers derived from emotional labour. However, through bringing their personality, interests and passions into a business conversation, it could be argued that the practitioners studied were allowing their employer to profit from their pleasure and thus their emotional labour since they (and therefore the organisation) were displaying 'genuine' motives and commitments (Bolton and Boyd, 2003:299) in their online work which made their online interactions credible and saleable. However, the practitioners in this study actually wanted to share their personal interests with people online; they did not feel obliged to do this. The only time where the professional and personal was deliberately demarked was in their use of social networking tool Facebook where some practitioners had both a personal and a professional Facebook account. However, even then, practitioners observed that some Facebook contacts moved from professional to personal as relationships developed.

Research into the place of emotion in public relations is inextricably bound up with the politics of gender, the subject of much discussion in public relations contexts. On the one hand, while authors such as Mackey (2003) suggest that feminisation of the values enshrined in public relations implies that "women are particularly suited to carry out public relations work," others (e.g. Froehlich (2004), Mitrook et al (1998)) suggest that while this may be true for the 'technician' roles in public relations (which encompass such skills as client liaison, negotiation, writing and creative work and through this, social media work) the senior positions still carry a largely masculine ideology. Farmer and Waugh (1999) found that women still believe that they will find it more difficult than men to advance into management, and that subtle sex discrimination still exists. Most day-to-day online work is carried out at public relations agencies at technician level, with senior management playing a less active or strategic role. 
Froehlich (2004) argued that female public relations professionals fall into a "friendliness trap" where their 'soft' skills of communication and co-operation are in direct opposition to the 'masculine' skills of leadership and assertion required at senior levels. This view is contentious in academic public relations circles - Grunig, Toth \& Hon (2000), who themselves align feminist values with model public relations practice, describe two opposing views of the effects of feminization of the industry, reporting that academics such as Lesly (1988) take a "gloom-and-doom prophecy accompanying the transition from male to female majority in this field" but "feminist scholars such as Rakow (1989)[...]suggest that women's emergence in public relations is an opportunity for more responsible and effective practice" Grunig, Toth \& Hon (2000, p.50).

Pierce (1995:31) suggests that certain organizations and individual positions are seen as 'female' because they involve tasks judged to be "expressive and personcentered, helping, nurturing and emphasizing." Brannan (2005) observes that gender is often used by practitioners as a way to build relationships with clients: "[F]emale CSRs (customer service representatives), for example, emphasised authenticity, which was signalled by terms such as "really getting to know" a particular client. This, of course, involved a reciprocal arrangement whereby clients would "really get to know" the female CSRs."

While this discussion may suggest that women are likely to be more prevalent (and successful) at online interactions than men, men interviewed in this research were more active on social networks which span both the personal and professional such as Twitter and were more likely to keep blogs in their own name. (Interestingly, despite around 65\% of PR practitioners being female (CIPR, 2010), it was far easier to find men to interview than it was women.)

\section{Practitioner stories}

This project aimed to discover, via semi-structured interviews, how practitioners engaged with others online when carrying out social media work, and the extent to which they used their own emotions and feelings in this work. To achieve this, telephone interviews were undertaken with seven public relations agency staff at different agencies across the UK. All interviewees worked for small to medium- 
sized independently-owned public relations agencies (between six and 50 employees). Such workplaces tend to have flatter and less hierarchical structures and consequently encourage (and reward) experimentation and personal development.

Interviewees were recruited on the basis that they were active in social networks and were employees (not company directors or owners) of agencies. All had active profiles on microblogging site Twitter, and/or had profiles on at least one other social network (such as Facebook or Linkedln). Many also kept a blog, and all made comments on public relations industry blogs, or blogs of relevance to their clients (this included technology, environmental, parenting and beauty blogs). Five of the interviewees, of which three were male, were aged under 30, the other two, both women, were in their 30 s and 40 s respectively.

Recruitment took two forms: A tweet requesting interview subjects was placed on microblogging site Twitter, which ultimately led to five successful interviews. However, this method resulted in an overrepresentation of men wanting to be interviewed (only two women put themselves forward), so in order to maintain a gender balance, an additional two women were sourced using the author's own contacts.

Interviews were informally structured around a number of themes relating to personal and professional social media use. In particular, practitioners were asked about their acquisition of social media skills, their views on carrying out work outside office hours, the role social media played in their leisure time, their perception of the views of colleagues and management to social media, and their enjoyment of using social media technologies for work and leisure.

The public relations/social media ideology is such that all practitioners interviewed claimed to be aware of the need for transparency and honesty in online dealings (for instance, through being clear about who they were and who they were representing in all online interactions) and as a result felt that the use of the personal was essential for effective online interactions - in other words, they were happy with 
using their 'self' in online interactions and understood the organisational rationale for it.

I had to go in (to an online forum) using a[...]personal perspective - the fact I was a mum-of-two interested in environmental issues. (Consultant, female, small regional PR agency)

You're on there talking about work, talking about home, talking about what you're doing - it does overlap a lot. Your audience[...]expect you to overlap. They don't want to know just what you're doing at work, they want to know more about you, and I think that's what builds their trust[...]Clients get to know who I am, and journalists get to know who I am and you're building a rapport with them. (Account manager, female, medium-sized regional PR agency) 
Thus, the use of the personal was seen as essential to effective social media interactions and desirable in terms of building relationships with contacts which could be of use either in their current role or in the future. In this sense, use of self was quite calculated, although also seen as adding to the enjoyment of social media use.

Although some interviewees stressed the need to limit social media use outside work ("If I had a choice I wouldn't got near a computer in the evening" (senior account executive, male, specialist London PR agency)) they did not articulate that their emotional skills were "overused (and) underappreciated" (Hochschild, 1983). Instead, they took pride in the fact that they were doing a good job - indeed, there was something of a pioneering spirit among the interviewees as they spoke of how they developed their own social media expertise, and were able to share their knowledge to the benefit of themselves, their clients and peers.

The interviewees also felt that their knowledge of a client's area of interest (often gained via monitoring social media discussion) benefited their work by allowing them to talk with more passion and knowledge about a subject, with one practitioner observing that she would have "felt like an impostor if not passionate about the subject" (account director, female, small regional PR agency). One younger male interviewee had many dealings with parenting and beauty blogs. Although he had no personal experience of either subject, he made sure that he got to know the bloggers well and worked hard to learn about the subjects. Most of this knowledge was acquired outside working hours on an informal basis and the issue of where (home or office) the knowledge should be acquired was never voiced as a problem.

Since the use of social media in public relations practice is a relatively new development, all interviewees were essentially self-taught in social media use (they had not learnt it at university or been taught by senior colleagues). Some interviewees saw knowledge acquisition in this area as a way of differentiating themselves from their colleagues, or adding an in-demand skill to their portfolio. Others saw it as something that they had to learn to progress their career.

I learnt 90\% myself. I've only been in PR for 18 months and (at the age of) 26 people at my age group at my level have a lot more experience - they've 
done PR at university, or worked up from work experience. I was aware that I had a lot of skills to catch up on. As I got more into it (social media) I realised that people at the agency weren't so into it, realised I could make my mark. As well as learning about traditional PR from nine to five, I could teach myself about digital PR to give myself an advantage. (Senior account executive, female, specialist PR agency)

I spent six months trying to work out what my voice would be, what I wanted to do and making mistakes[...](I) wanted to spend time finding out how it worked so a proportion (or the learning) took place at home, finding time to read[...]there was a five or six month period when it became all consuming, I was so hungry to work, Would get home, laptop would go on. There's probably a bit more balance (now) than there was. (Consultant, male, London communications agency)

Practitioners were using their free time to learn a new skill which they felt would benefit them in the future. Of course, it also benefited their employer - and while practitioners were clearly aware of this, their explanations were in terms of it benefiting their clients and themselves. They wanted to do (and be seen to do) the best for everyone they worked with, confirming Brannan's (2005) view that their interactions were not simply selfish; they were working as part of a team. Some practitioners at smaller regional or specialist agencies admitted that the senior agency staff did not share their passion for social media and even treated it as something of a fringe activity. However, these practitioners also felt that their skills were being learnt for the purpose of future career progression so did not feel that their time was being wasted.

Writing of personal trainers, Smith Maguire (2008) claims that they "straddle two worlds considered mutually exclusive: the service-orientated world of the professional and the self-interested realm of the entrepreneur." There are parallels here between the trainers and the public relations practitioner working online. Because they need to build their own 'personal brand' in order to demonstrate their expertise to future employers, practitioners are entrepreneurs, and have the 'luxury' to do this as part of their own job. But they are also employees, paid to tow a 
corporate line across social media platforms and analysis of interviews suggested that staff were using their objective self to communicate, drawing on both their past experiences, current interests and collective values of their organisation.

All interviewees spent time online outside the office carrying out work for their employers. Interestingly, those who worked for agencies which promoted their social media services as part of their business offer were least likely to work long hours online outside the office. These practitioners were encouraged to spend time at work carrying out both business and personal online activities since even their personal work benefited the clients (for instance in terms of building up 'friendly' relationships with journalists). Consequently, performing work-related social media tasks outside the office was seen as inevitable, but was not viewed negatively unless it became excessive.

For one of our Twitter accounts our followers get active at about 7:00p.m. so I go and see what they are talking about so I can discuss it the next day. It's not all going to happen between nine and five so as long as you don't spend too much time on it (it's OK). (Account manager, male, London consumer PR agency)

It's my own choice to do it - l'll occasionally retweet something for a client (in the evening) - I don't mind, I'm quite proud of it (my client's Twitter account). I convinced the client to let me do it (set up a Twitter account) and it's my baby. (Senior account executive, female, specialist PR agency).

It appeared that practitioners only spent a considerable amount of time on a project outside the office (more than two hours a day) if a specific campaign demanded it. Nonetheless, the creep of work into the home, even if only for a relatively short period of time, is a common feature of new media work, further blurring the distinction between home and office. Such a dissolution of the public-private divide is a central feature of the process of informalisation (Wouters,1989) in the workplace where social media activity of a personal level is seen as acceptable within the workplace with one male interviewee commenting that checking Facebook had "replaced the cigarette break." 
As Hughes (2003) argues, emotion was never a private act separate from work, and this becomes increasingly apparent as workplaces become relatively more relaxed and work increasingly takes place outside the workplace. Hughes argues that emotions have a place with the workplace, and that the worker is required to use them in a flexible way to deal with the different demands placed on them. While this can flexibility can be positive for the employee, in that they can make decisions and adapt their working patterns independently, it further blurs the boundary between work and non-work. Nonetheless, the practitioners interviewed did not see this as problematic, as work was not seen as something which should only take place in the office, but something which could be done for relaxation, or even to fill a dull evening.

l'd (carry out social media work) in the evenings when I would normally be on Facebook [...]To me it like going to the pub when working on a beer (brand) and mentioning it to my friends. (Account director, female, small regional PR agency)

However, another practitioner did not see online interactions which straddled the personal/professional divide as being so natural and, while he took enjoyment from them, sounded a note of caution.

I think that there is an accepted way to behave (when using social media) and if you act a bit differently and your values don't sit well people tend to highlight things. It's not like having a conversation where there's a spread of opinion[...]people can be more vocal or opinionated on Twitter when in real life they might not be as inclined to behave this way. (Consultant, male, London communications agency)

Thus, the risk of damaging their own personal brand was too great to give practitioners the freedom to talk online in a completely relaxed way, even in personal social media use. Since the personal and professional were so entwined, the only way they could truly be 'themselves' was via creation of a pseudonym - and only 
one practitioner admitted to doing this. This suggests that social media has helped the public relations role to become inextricably bound up with personal identity.

As Gill (2007) observed, people working in new media have "an extraordinary degree of enthusiasm and ardour" for their work, and this feeling spreads to those working in public relations - indeed, the practitioners interviewed spoke with real passion for their work. Instead of simply fulfilling their role, they were also "giv(ing) their labour voluntarily and enjoy(ing) it" (Kennedy, 2009: 179). Of course, there is a problem with this view - as Terranova (2000:online) observes, net labour is often unwaged and exploited with "punishing work rhythms and[...]ruthless casualisation." In order to represent their organisation or client satisfactorily, the interviewees worked in the evenings and at weekends in order that they could make the most of online opportunities. To not do this was never considered, such was the commitment of interviewees to their team, their employers, and their own personal brand. The contested terrain of such perspectives (net labour given voluntarily for personal enjoyment and gain on one hand, unwaged and exploited on the other) are worthy of discussion. As Kennedy (2009) observes, the binary division of new media workers as either creative or enslaved is inadequate and does not take into account the subtleties or complexities of these roles caused in part by decline of the career (Gill, 2007) and the entrepreneurial nature new media workers who do not see career and home as separate entities (none of the interviewees felt that carrying out a limited amount of work at home was worthy of complaint with all enjoying it to some degree, as explained above). In this sense, the practitioner has (at least) a dual identity when operating online, with their roles "overlapping in time and space" (Smith Maguire, 2008:216).

The interviewees did not voice any complaints regarding the use of what was essentially their personal capital for the benefit of their employer/clients, either though carrying out work in their own time or using their personal contacts and interests and personality to promote their client. Indeed, it was necessary and even enjoyable (although at times their reasons for engaging online were quite calculated). Commenting on her Twitter use, a female senior account executive with a specialist agency observed: "I let out quite a bit of my own personality[...]talk about fun things that I think are interesting (and) try to assert my personality." 
It would be clumsy to suggest that practitioners were giving their time and emotion simply to further either their career or their employer's interests. The interviews showed that practitioners spent time on social media outside working hours for many reasons, which can be summarised as:

- their own self-esteem (seen to be doing a good job)

- the furtherance of their own career or 'personal brand'

- the success of the campaign (and through this, the success of their employer)

- their commitment to the client and their employer

- the pleasure derived from working as a team and sharing ideas and experiences

- the learning and developing of a new skill (online public relations)

- sharing of ideas and knowledge

Terranova (2000) argues that practitioners would not be aware of their own exploitation and that their labour should not be seen as 'employment' insofar as they are donating their time to their employers. However, it is difficult to unpick what work a practitioner gives for 'free' and what is paid employment, such is the flexibility of new media careers (and what straddles the two, for instance when a practitioner is using their work to build their own personal brand or is learning about social media by experimentation on a client).

It is through this investment in the personal that they "legitim(ise their) goods and activities through an investment of personal belief" (Smith Maguire, 2008:224). Thus, the use of the personal is vital to organisational success; salaries are not simply being paid for skills and knowledge but also for the practitioner's personality and contacts.

Poynter (2002:255) claims that that professional service workers have "real discretion over the re-engagement in the labour process, including discretion over their hours of work, their interactions with clients (and is) therefore a relationship of equals." However, this assumes that the control is not dictated by economic pressure (the need to get the job done well or stay in employment) or peer pressure. Many 
public relations agencies operate a relatively flat hierarchical structure, with practitioners grouped into small and flexible teams working for a number of separate clients. Despite a soft approach to human resource management, consultants within a public relations agency are working for a service which is "intensely competitive" (Pieczka 2006a:304) in terms of the need to win new clients (or retain them) since clients are freedom to move to another agency. Thus, it is an environment which can lead to a contradiction between management claims of flexibility and the reality of working in a culture where failure is not tolerated.

\section{Conclusion}

Interviewees did not allow the 24-hour nature of new media to invade all aspects of their life, despite what was, for some, the temptation to do so. Although additional hours were worked in the evenings and weekends or while travelling, none saw the additional unpaid hours as anything more than a necessary part of their job, although views were mixed as to whether they did this work out of pleasure or duty (or both) or simply from habit. This additional time spent on work was not viewed negatively or as something which did not benefit employees despite "serving the interests of the employers in maximising surplus value." (Kent and Taylor,1998: 85). In this sense, this corresponds with Macdonald and Sirianni's (1996) view of call centre employees as the product, with the success of the project not dependent just on practitioner skill but the extent to which staff were willing to commit themselves emotionally to a certain project, corresponding with the idea of personal branding - the commodification of self.

Johannsen (1990) and Yeomans (2007) et al have highlighted the importance of empathy in public relations communications in order for a public relations practitioner to fully achieve many of the competencies expected of them. The fact that the practitioners interviewed enjoyed their online interactions and understood the social context of the online activity in which they were involved confirms Kent and Taylor's (2002:27) view that empathy is a critical part of public relations dialogue "because practitioners can improve their communication by 'walking in the shoes' of their publics" and thus have an understanding of the position that they inhabit. However, emotional labour is the commodification of such empathy, and while the practitioners in this study did not take issue with the public relations agency using their personality 
or personal connections for financial gain, it is not inconceivable that such a situation could arise or that a higher value than a typical public relations salary could be demanded by a practitioner for the online goodwill and contacts they held.

These first research findings have several implications for the way in which we can view social media engagement and emotional labour, especially when viewed through the prism of public relations practice. Firstly, online conversations took emotional commitment beyond the boundaries of previously- researched journalistpractitioner relationships since practitioners were using their personal backgrounds and interests in a myriad of relationships. They brought more of their personal life into their work, and furthermore took the work home due to the portable nature of online work and the 24-hour nature of online communications. However, despite the incursion of work into all aspects of their domestic life, practitioners did and did not have an issue with their 'self' being used as a commodity for the client - furthermore, they did not see any ethical or moral contradiction so doing.

This brings us to a second point; whether the use of social media reaffirmed the roles and rules of existing public relations practice (and thus, any gender inequalities inherent in it) and even mirror the inequalities seen by Gill $(2002,2007)$ in new media work. For agencies which had a traditional outlook and focussed on typical public relations activities such as media relations and events, social media work was seen as something unusual or non-core, with the result that practitioners spent more time performing it at home. Since this was work which could be suited to a domestic setting, this could be seen as further compounding any gender or other inequalities as it kept success largely private. In this scenario, it would not be clear to management how a client's business objectives had been achieved, or even if the activity had value. The smaller sample size due to the nature of in-depth interviews may have skewed the findings, but the interviewees who worked for such agencies were all women. This suggests a need for further quantitative study to establish the extent of such inequalities.

Bradley (1999:210-211) notes that despite women in service industries being more confident of their own value, "managerial and professional men[...]are able to use their positional power at work[...]and keep women confined to niche positions." 
Although the use of social media within public relations could be argued to still be part of the technician public relations role, the importance given to it by public relations commentators suggest that it may not occupy this position for long, potentially leading to a situation where a junior role could be seen to have a masculine ideology due to a focus on technical skills and, in some scenarios (for instance, 'Twitter pitches,' a need to aggressively self-promote. This shift has implications which, while outside the focus of this article, would benefit from further discussion.

Finally, the complex issue of using the personal to promote the client was discussed and understood by practitioners, but was legitimised through its 'transparency' (this rationale is also used in public relations literature - for instance Brown (2009), Phillips and Young (2009)). However, the reality is more complex than this. The emotions and domestic life of public relations practitioners are becoming, via social media, a 'product' possessed both by the individual and by the public relations agency, and contribute not just towards the competitive success of an organisation but to the individual's career success (and self-esteem) as well. However, this straddling of culture and economy possibly benefits future employers more than it does the practitioner, so while the practitioner is both being exploited by the situation and exploiting the situation for their own personal gain, they are also ensuring that they can be exploited again in a future job.

\section{BIBLIOGRAPHY}

Aldoory, L. \& Toth, E. (2002) Gender discrepancies in a gendered profession: A developing theory for public relations. Journal of Public Relations Research, March 2002, vol 14(2), pp. 103-27

Aldoory, L. (2005) A re-conceived feminist paradigm for public relations: a case for substantial improvement, Journal of Communication, December 2005, Vol, 55:4, pp. 668-84 
Andrejevic, M. (2008) Watching Television Without Pity: The Productivity of Online Fans, Television New Media, January 2008, vol. 9:1, pp. 24-46

Bolton, S. C. \& C. Boyd (2003) Trolley dolly or skilled emotion manager? Moving on from Hochschild's Managed Heart, Work, Employment and Society, June 2003, vol. 17:2, pp. 289-308.

Bradley, H. (1999) Gender and Power in the Workplace. Basingstoke: MacMillan Press

Brannan, M (2005) Once More With Feeling: Ethnographic Reflections on the Mediation of Tension in a Small Team of Call Centre Workers, Gender, Work and Organization, September 2005, Vol. 12:5 pp. 420-439

Brown, R. (2009) Public Relations and the Social Web: How to Use Social Media and Web 2.0 in Communications. London: Kogan Page

Chartered Institute of Public Relations (2010) CIPR State of the PR Profession Annual Benchmarking Survey. [WWW] Available at: http://www.cipr.co.uk/content/policy-resources/research-reports/state-prprofession

Farmer, B. \& Waugh, L. (1999) Gender differences in public relations students' career attitudes: A benchmark study. Public Relations Review, Summer 1999, vol. 25:2, pp. 235-249

Froehlich, R. (2004) Obstacles for women's future and career in public relations: feminine and feminist values as a "friendliness trap?" Paper presented at the ANZCA conference 2004, Sydney, Australia. [WWW] Available at: http://conferences.arts.usyd.edu.au/viewpaper. php?id=94\&cf=3 
Gill, R. (2002) Cool, Creative and Egalitarian? Exploring gender in projectbased new media work in Europe, Information, Communication and Society, Vol. 5:1, pp. 70-89

Gill, R (2007) Technobohemians the new cybertariat? New media work in Amsterdam a decade after the Web. [WWW] Available at:

http://www.networkcultures.org/networknotebooks

Hochschild, A.R. (1983) The Managed Heart. Berkley and Los Angeles, California: University of California Press

Hughes, J. (2003), 'Intelligent hearts': emotional intelligence, emotional labour and informalization, working paper No. 43, Centre for Labour Market Studies, University of Leicester, Leicester

Kennedy, H. (2009) Going the extra mile: Emotional and commercial imperatives in New Media Work, Convergence, (2009) vol.15:2, pp. 177-196

Kent, M.L. and Taylor, M. (1998) Building dialogic relationships through the World Wide Web. Public Relations Review, Fall 1998, vol. 24:3, pp. 321334.

Kent, M.L. and Taylor, M, (2002) Toward a dialogic theory of public relations, Public Relations Review, February 2002, Vol. 28:1, pp. 21-37

Korczynski, M (2003) Communities of coping: Collective emotional labour in service work, Organization; February 2003, vol.10:1, pp. 55-79

Leadbeater, C. \& Oakley, K. (1999) The Independents: Britain's new cultural entrepreneurs. London: Demos

Macdonald C. \& Sirianni C. (1996) The Service Society and the Changing Experience of Work'. In Macdonald C. \& Sirianni C. (eds) (1996) Working in 
the Service Society, Temple University Press, Philadelphia.

Mackey, S. (2003). Changing vistas in public relations theory. [WWW] Available at:

http://praxis.massey.ac.nz/fileadmin/Praxis/Files/Journal Files/issue1/ refereed articles paper3.pdf

Mitrook, A., Wilkes, K.V. and Cameron, G.T. (1998). Dealing with the feminization of the field: attitudes and aptitudes of college women in public relations. AEJMC Conference Papers. [WWW] Available at:

http://list.msu.edu/cgibin/wa?A2=ind9812b\&L=aejmc\&T=0\&F=\&S=\&P=4096

Munter, M. (2005). Guide to Managerial Communication, Seventh Edition. New Jersey: Prentice Hall.

Pieczka, M. (2006a) Public Relations Expertise in Practice. In L'Etang, J. and Pieczka, M. (eds) Public Relations: Critical Debates and Contemporary Practice. Mahwah, NJ and London Lawrence Erlbaum Associates

Pieczka, M. (2006b), 'Chemistry' and the public relations industry: an exploration of the concept of jurisdiction and issues arising. In L'Etang, J. and Pieczka, M. (eds) Public Relations: Critical Debates and Contemporary Practice, Lawrence Erlbaum Associates, Mahwah, NJ and London.

Pierce, J.L. (1995) Gender Trials California: University of California Press

Phillips, D. and Young, P. (2009) Online Public Relations. London: Kogan Page

Poynter, G. (2002) Emotions in the labour process. European Journal of Psychotherapy, Counselling \& Health, September 2002, Vol. 5:3, pp. 247261 
Scoble, R. and Israel, S (2006) Naked Conversations. Hoboken, New Jersey: John Wiley \& Sons

Smith Maguire, J. (2008) The personal is professional: Personal trainers as a study of cultural intermediaries, International Journal of Cultural Studies, June 2008, Vol. 11:2, pp. 211-229

Terranova, T. (2000) Free labour: producing culture for the digital economy. [WWW] Available at: http://www.nettime.org/ListsArchives/nettime-1-0004/msg00013.html

Van Ruler, B. (2005), Commentary: professionals are from Venus, scholars are from Mars. Public Relations Review, June 2005, Vol. 31:2, pp. 159-173

Wouters, C. (1989) The sociology of emotions and flight attendants:

Hochschild's Managed Heart, Theory, Culture and Society, February 1989, Vol. 6:1, pp. 447-50.

Yeomans, L. (2007) Emotion in public relations: a neglected phenomenon, Journal of Communication Management, 2007, Vol 11:3, pp. 212-221 